\title{
A visão dos alunos da educação profissional de nível médio sobre as políticas de permanência estudantil no IFPA
}

The students vision of professional education in the high school about the student permanence polictics in the IFPA

La visión de los estudiantes de educación de nivel medio sobre las políticas de permanencia estudiantil no IFPA

\author{
* Maria Cristina Afonso Ferreira \\ Pedagoga no Instituto Federal do Pará, Paragominas, Pará, Brasil. \\ fercris2000@yahoo.com.br \\ ** Maria de Fátima Matos de Souza \\ Professora doutora na Universidade Federal do Pará, Belém, Pará, Brasil. \\ fmatoz@gmail.com
}

Recebido: 20 de setembro de 2018

Aprovado: 20 de novembro de 2018

\section{RESUMO}

O texto integra uma pesquisa de mestrado que busca analisar a implementação das políticas de permanência no interior de um dos campi do Instituto Federal de Educação do Pará (IFPA), demarcadas no estudo como as ações do Programa Nacional de Assistência Estudantil. A abordagem é qualitativa, desenvolvida a partir da estratégia do estudo de caso, e utiliza-se dos instrumentos de coleta de dados: pesquisa documental e entrevistas semiestruturadas com seis alunos dos cursos de educação profissional de nível médio integrado e subsequente; situa-se as visões destes alunos sobre as políticas de permanência e, no que diz respeito às unidades de análise temática, sobre a escolha das ações e a permanência no curso. Os dados revelam que no campus do IFPA há a promoção do Fórum Interno Estudantil para a escolhas das ações integrando os alunos dos cursos de nível médio, mas que precisa aprimorar os mecanismos de participação em atenção às necessidades dos alunos. Identificouse que os alunos atribuem à política de assistência estudantil estrita influência com a permanência no curso. Conclui-se que no campus as ações da política de permanência, em sua maioria, vinculam-se ao pagamento de auxílios financeiros pelas limitações orçamentárias. 


\section{Tusm eltubahá}

Palavras-chave: Políticas de permanência estudantil; Educação profissional de nível médio; Instituto federal de educação do Pará.

\section{ABSTRACT}

This article is part of a master's research about a perspective of the permanence politics inside one campi of the Instituto Federal de Educação do Pará (IFPA), pointed in this study as actions of the National Program of Student Assistance. The approach is qualitative, beacause it is developed by the strategy of study case, and uses data samples; documentary research and semi structured interviews with six students of integrate and subsequence High School Professional Education courses. It is point out the visions about the Student Permanence Politics, considering the thematic analysis unitis, on the choose of actions and permanence in the course. The data collected revealed that in the IFPA campus have a Internal Student Forum to the action choices, integrating the students of High School, but is necessary improve the ways of students participate of it according to the needs of them. It was identified that the students attribute to the policy of student studies strict influence with the permanence in the course. I conclude that in the campus the Student Permanence politics actions, in the most part of time is linked with the payment of financial aid by budget contains.

Keywords: Keywords: Student permanence politics; Professional education in the high school; Instituto federal de educação do Pará.

\section{RESUMO}

El texto integra una encuesta de maestría que busca analizar la implementación de las políticas de permanencia en el interior de uno de los campus del Instituto Federal de Educación de Pará (IFPA), demarcadas en el estudio como las acciones del Programa Nacional de Asistencia Estudiantil. El enfoque es cualitativo, desarrollado a partir de la estrategia del estudio de caso, y se utiliza de los instrumentos de recolección de datos: investigación documental y entrevistas semiestructuradas con seis alumnos de los cursos de educación profesional de nivel medio integrado y subsiguiente; se sitúan las visiones de estos alumnos sobre las políticas de permanencia y, en lo que se refiere a las unidades de análisis temático, sobre la elección de las acciones y la permanencia en el curso. Los datos revelan que en el campus del IFPA hay la promoción del Foro Interno Estudiantil para las elecciones de las acciones integrando a los alumnos de los cursos de nivel medio, pero que necesita perfeccionar los mecanismos de participación en atención a las necesidades de los alumnos. Se identificó que los alumnos atribuyen a la política de asistencia estudiantil estricta influencia con la permanencia en el curso. Se concluye que en el campus las políticas de permanencia se restringen al pago de ayudas financieras, se restringe a este frente por las limitaciones presupuestarias. 


\section{OFEM H \\ 15SN: 1984-6444

Palavras-chave: Políticas de permanencia estudiantil; Educación profesional de nivel medio; Instituto federal de educación de Pará.

\section{Considerações iniciais}

O presente artigo integra uma pesquisa de mestrado do Programa de PósGraduação em Currículo e Gestão da Escola Básica - PPEB da Universidade Federal do Pará - UFPA. Busca-se com a investigação analisar a implementação das políticas de permanência estudantil nos cursos de educação profissional de nível médio, em um dos campi do Instituto Federal de Educação do Pará - IFPA, no período que compreende os anos de 2012 a 2017. A abordagem insere-se nas discussões contemporâneas do direito à educação escolar, de ter acesso e permanência na escola básica e superior pública.

A pesquisa é do tipo qualitativa, pois permite a liberdade de definir os referenciais e percursos metodológicos diversificados (ANDRÉ, 2001), de maneira a compreender o objeto do estudo a partir dos objetivos da investigação. Possibilita considerar que o objeto de investigação pode sofrer modificações no percurso da pesquisa (TRIVIÑOS, 1987), reconhecendo as influências no contexto social e institucional em que se materializa.

Utiliza-se como estratégia investigativa o estudo de caso em vista a temática "política de permanência estudantil na educação profissional de nível médio" vincularse a um contexto sócio histórico de uma instituição de ensino que possui similaridade com a universidade, que tem origem em escolas de educação básica e apresenta uma proposta de verticalização de ensino que engloba os cursos de formação inicial e continuada, a educação profissional de nível médio, a graduação e a pós-graduação, considerando a lei $n^{\circ} 11.892 / 2008$, que criou os Institutos Federais de Educação.

As políticas de permanência estudantil, aqui investigadas, no IFPA atendem o Decreto $n^{\circ}$ 7.234/2010, que estabeleceu o Programa Nacional de Assistência estudantil - PNAES, com ações definidas a ofertar aos estudantes das instituições federais de ensino, como: moradia, alimentação, transporte, atenção à saúde, inclusão digital, cultura, esporte, creche, e apoio pedagógico, acesso, participação e 


\section{DFM

aprendizagem de estudantes com deficiência, transtornos globais do desenvolvimento e altas habilidades e superdotação.

Pretende-se apresentar aspectos da pesquisa documental e das entrevistas semiestruturadas em atenção a um dos objetivos da pesquisa de saber a visão dos alunos em relação às políticas de permanência estudantil e à influência dessas em sua permanência nos cursos técnicos de nível médio, integrado e subsequente em informática e edificações.

Apresenta-se a discussão nos itens: $A$ educação profissional e os Institutos Federais de Educação, no qual se destaca aspectos da história da educação profissional e dos institutos federais de educação, particularmente no processo de expansão às regiões do Brasil; As políticas de Permanência Estudantil no Instituto Federal do Pará, que trata da descrição das normativas institucionais que subjazem a implementação das ações desta política; e As políticas de permanência estudantil: a visão dos alunos dos cursos de educação profissional de nível médio, no qual se discorre sobre as políticas ofertadas pelo campus investigado do IFPA e o posicionamentos dos alunos, sobre as influências das mesmas para a permanência nos cursos.

\section{A educação profissional e os institutos federais de educação}

Apresenta-se aspectos legais e históricos da educação profissional a partir da década de 1980 até os dias atuais, como o processo de transformação e reestruturação dos Centros Federais de Educação em Institutos Federais de Educação a partir da Lei no 11.892/2008, e o processo de expansão da rede nas regiões do país, bem como as mudanças inseridas no contexto da modalidade a partir da gestão do Presidente Michel Temer.

A educação profissional, na sua história, é carregada de elementos que coadunam para o desenvolvimento de um projeto educacional que esteve voltado a atender ideias das classes favorecidas política e econômica. Traz consigo elementos de uma sociedade que discrimina o trabalho manual que, desde a primeira república até início do século XX, apresenta características estritamente assistencialistas. Adquire mudança de perspectivas apenas com o desenvolvimento industrial no 


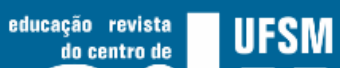

contexto do Brasil, que veio responder ao 'necessário' preparo técnico para atender o mercado de trabalho e ao projeto capitalista de desenvolvimento social (MANFREDI, 2017).

Foi nos anos de 1980 que emergiram as lutas em prol de uma educação pública que viesse atender os interesses das classes economicamente desfavorecidas, tanto que fora nesta década que houve a aprovação da Constituição Federativa do Brasil de 1988, considerada a constituição cidadã pelo avanço trazido em relação aos direitos sociais e políticos, em vista ao regime militar anteriormente adotado no país.

Nesse cenário havia a disputa de um projeto de educação profissional que trazia:

[...] a discussão em torno do ensino médio e da educação profissional, ocupou um lugar importante nos conflitos que atravessavam o campo educacional. Só para mencionar um exemplo, enquanto uns pretendiam que o Brasil fosse o primeiro país capitalista a adotar a politecnia como princípio educativo no ensino médio e queriam ver os germens dessa pedagogia nas escolas técnicas existentes, outros cerravam fileiras na defesa dos sistemas de aprendizagem controlados pelo patronato, rejeitando o controle estatal e/ou a participação dos sindicatos de trabalhadores em sua gestão (CUNHA, 2000, p. 244).

Tais disputas foram representadas nas legislações posteriores, com alguns avanços em 1996 a partir da promulgação da Lei de Diretrizes e Bases da Educação Nacional, como fruto do intenso debate entre as forças conservadoras e progressistas, que no seu Título $\mathrm{V}$ trata dos níveis e modalidades de educação e ensino, apresenta a educação profissional integrada às diferentes formas de educação, trabalho, à ciência e à tecnologia, traz em seu bojo a finalidade de formar para o permanente desenvolvimento de aptidões para a vida produtiva.

Esta articulação foi posta em cheque com a promulgação do Decreto no 2.208 de 17 de abril de 1997 que regulamentou o parágrafo 2ํำ do artigo 36 e os artigos 39 a 42 da LDB, estabeleceu a separação formal entre ensino médio e técnico, elaborando, para cada um, organização e currículos específicos, regendo-se pelo princípio da flexibilidade: "com um ensino modular cujo intento é oferecer maiores oportunidades de entrada e saída do sistema, tendo em vista a empregabilidade do aluno" (SHIROMA; MORAES; EVANGELISTA, 2011, p. 76).

O ensino técnico se organizou em três níveis: básico, técnico e tecnológico, nesse sentido: 


\section{Tusm \\ 15SN: 1984-6444

O divórcio entre o ensino médio e técnico parece ter respondido numa só cartada, a mais de um interesse. Suprimiu-se o estatuto de equivalência, recuperando uma antiga ambição da legislação educacional brasileira; parte do ensino pós-compulsório foi transformado em estritamente profissionalizante, adquirindo caráter terminal, e parte manteve-se propedêutico. Reeditando a velha dualidade, encaminha jovens de classes sociais distintas para trajetória diferenciadas não só educacionais, mas sobretudo sociais e econômicas. A novidade é a criação do nível básico, dentro do ensino técnico, que independe da escolaridade do aluno. (SHIROMA; MORAES; EVANGELISTA, 2011, p. 77).

O governo atribuiu, segundo os autores, ao setor privado, a incumbência de oferecer a formação geral da força de trabalho, além da presença do público no privado muito latente, no crescente exorbitante de convênios com empresas e serviços no nível médio de ensino. Outro elemento inerente a essa separação é a contenção de vagas para o ensino superior, na medida que dá um caráter de terminalidade ao nível técnico de ensino.

Com a mudança de governo estruturado em meio aos conflitos econômicos e políticos, uma vez que agregava forças antagônicas, promulga-se o Decreto oㅡ $5.154 / 2004$, que regulamenta o parágrafo $2^{\circ}$ do art. 35 e art. 36 e os arts. 39 a 41 da LDB, que indica a reinstauração de um novo ponto de partida para a travessia, no sentido de consolidar a educação profissional e o ensino médio por meio de um projeto no qual o horizonte deste seja a formação unitária e politécnica, centrada nas bases do trabalho, da ciência e da cultura, no estabelecimento de uma relação mediada por uma formação profissional específica que possa se consolidar em diferentes níveis e modalidade de ensino (FRIGOTTO; CIAVATTA; RAMOS, 2012).

O citado decreto carrega consigo elementos do projeto social dos grupos antagônicos que formaram o governo do Partido dos Trabalhadores - PT. Representa a permanência de forças conservadoras no manejo do poder e manutenção de seus interesses, ao mesmo tempo que demonstra a timidez política de um governo no caminho de um projeto nacional de desenvolvimento popular e de massa, que sinaliza reformas estruturais concomitantes (FRIGOTTO; CIAVATTA; RAMOS, 2012).

No âmbito dos CEFET - Centro Profissional de Educação Profissional e Tecnológica, há a promulgação da Lei no 11.982/2008, que criou os Institutos Federais de Educação Profissional e Tecnológica pela agregação/reorganização de antigas instituições de educação profissional: Escolas Técnicas Federais, Centros Federais 




de Educação (CEFET) e Escolas Agrotécnicas ${ }^{1}$. A partir daí, foram criadas mais 208 unidades, como ilustrado no Gráfico 1 a seguir:

Gráfico 1- Expansão da Rede Federal de Educação Profissional, Científica e Tecnológica - Em Unidades.

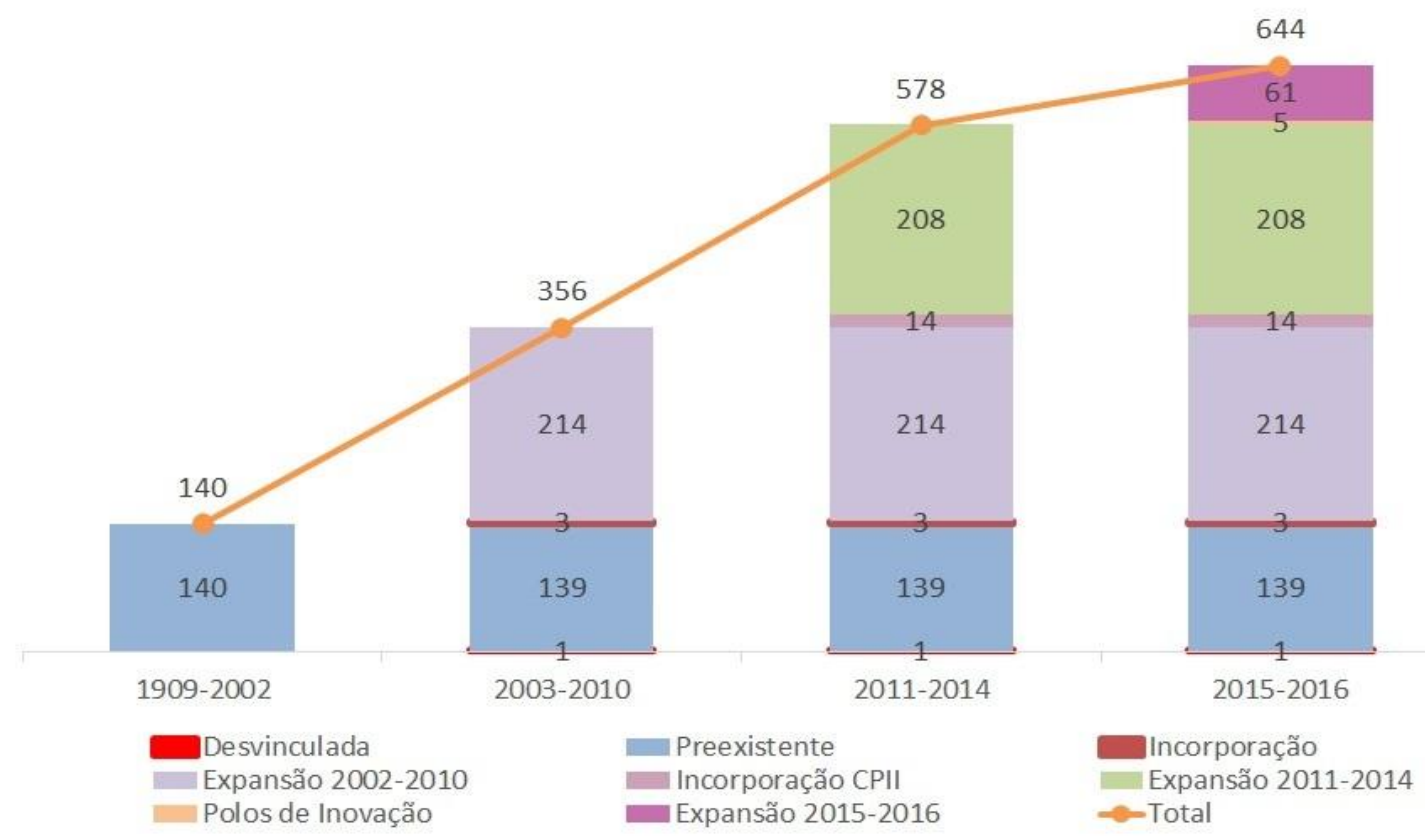

Fonte: Portal da Rede Federal de Educação Profissional e Tecnológica (2016) ${ }^{2}$

Percebe-se, por meio desse gráfico, que houve um aumento quantitativo de campi dos Institutos, o que demonstra o avanço das políticas públicas para a educação profissional na primeira década e meados da segunda década do século XXI. Por exemplo, entre 2003 a 2010, foram 214 unidades que passaram a compor a mencionada rede, aumento que permitiu novas oportunidades para o público jovens e adultos, carente de formação técnico-profissional, na pretensão de romper com as orientações das instituições dessa natureza, que atendiam as diferentes orientações de governos em época distinta a essa.

Destaca-se que, com essa expansão, há outra dimensão associada à rede federal de educação profissional e tecnológica que diz respeito à competência da

1 Foram 31 Centros Federais de Educação Tecnológica (CEFET), 75 Unidades de Ensino Descentralizadas (UNED), 39 Escolas Agrotécnicas Federais (EAF), 7 Escolas Técnicas Federais (ETF); 8 escolas vinculadas a universidades se atrelaram para compor a Rede Federal de Educação Profissional, Científica e Tecnológica.

2 Disponível: <http://redefederal.mec.gov.br/>. 


\title{
usm

instituição de tecer em seu interior propostas de inclusão social alternativas pautadas nessa realidade, e não apenas pelas políticas de governo (BRASIL, 2010b).

Dentro desse processo, apresenta-se no Gráfico 2 o número de municípios atendidos com a expansão da referida Rede:

Gráfico 2 - Quantidade de Municípios atendidos com a expansão da Rede Federal de Educação Profissional, Científica e Tecnológica

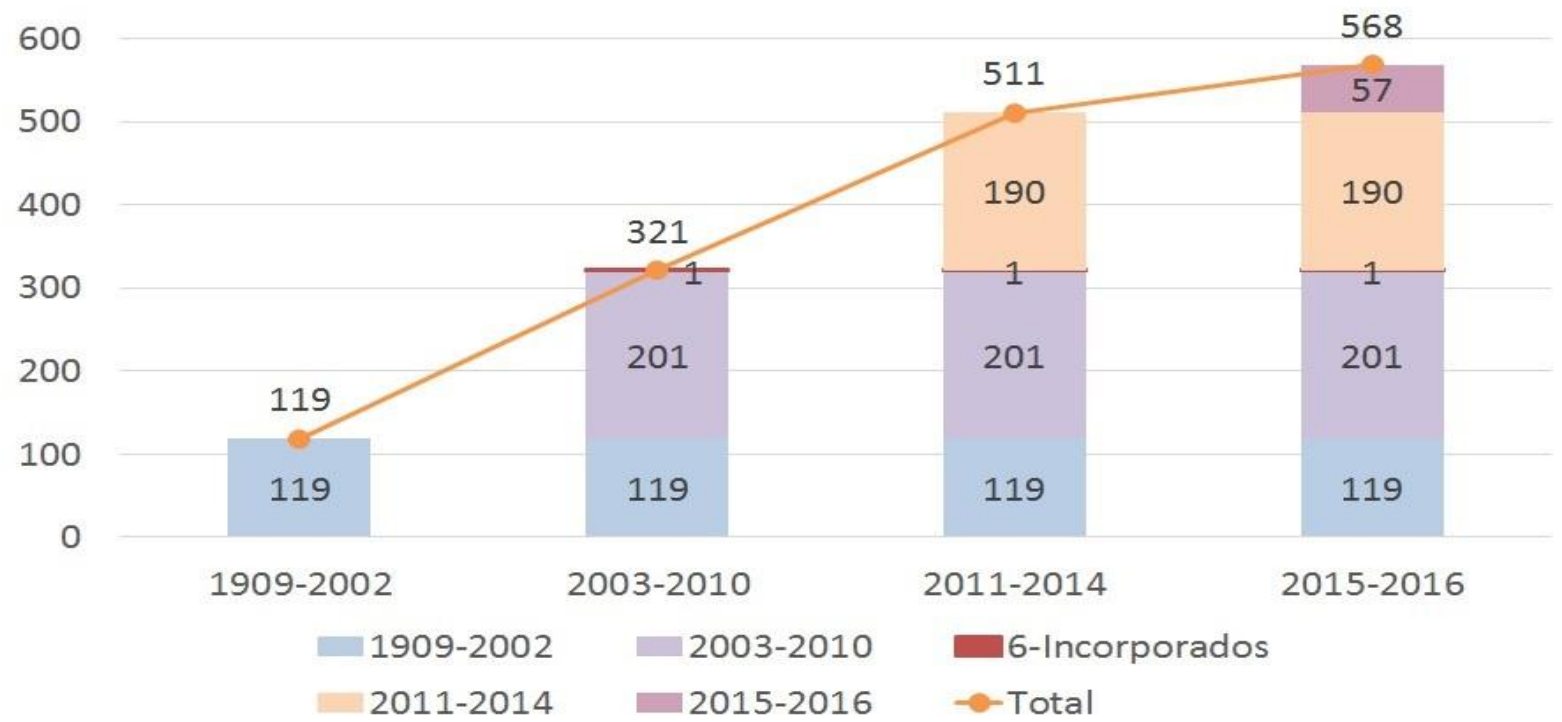

Fonte: Portal da Rede Federal de Educação Profissional e Tecnológica (2016) ${ }^{3}$

Há uma significativa abrangência da referida rede quando se trata de números de municípios atendidos, atualmente são 568 que recebem os campi; destaca-se, ainda, que essas unidades não se restringem a atender apenas o município onde estão instalados, mas também toda uma região, chamada de área de abrangência. Para contribuir com o desenvolvimento local e regional na perspectiva de construção da cidadania, sem perder a dimensão do universal:

\begin{abstract}
O diálogo vivo e próximo dos Institutos Federais com a realidade local e regional objetiva provocar um olhar mais criterioso em busca de soluções para a realidade de exclusão que ainda neste século castiga a sociedade brasileira no que se refere ao direito aos bens sociais e, em especial, à educação. No local e no regional, concentra-se o universal, pois nada no mundo seria em essência puramente local ou global. A interferência no local propicia alteração na esfera maior (BRASIL, 2010b).
\end{abstract}

\footnotetext{
${ }^{3}$ Disponível em: <http://redefederal.mec.gov.br/>.
} 


\section{Uism \\ 15SN: 1984-6444

Esse desenvolvimento precisa estar no conjunto das políticas públicas que integram a região, e não apenas a uma única agência desse processo de desenvolvimento, por isso os institutos federais situam-se em uma determinada área geográfica, associados a projetos e programas mais amplos e globais, constituindo em um espaço fundamental na construção de caminhos com vista ao desenvolvimento local e regional (BRASIL, 2010b).

A expansão leva a educação profissional de nível médio às diferentes regiões do país, e no caso do Pará, com a transformação das escolas técnicas e Agrotécnicas de Belém, Castanhal e de Marabá Rural (IFPA, 2014), bem como a criação de novas unidades, como é o caso do campus investigado que surge com esta lei, leva à possibilidade de acesso à educação pública de uma rede que apresenta um projeto educacional relevante para a formação do jovem público da Educação Profissional de Nível Médio.

Entretanto, destaca-se, no ano de 2016, uma quebra nesse projeto, com a ascensão à presidência do Brasil de Michel Temer, chamado de golpe político por autores como Frigotto (2016) que, entre algumas reformas, pode-se citar, no contexto da educação profissional e do ensino médico a Lei no 13.415 de 16 de fevereiro de 2017 como principal modificação referente ao caput do Art. 36 da LDB, Lei no 9394/1996, que passa a apresentar a seguinte redação:

[...] o currículo do ensino médio será composto pela Base Nacional Comum Curricular e por itinerários formativos, que deverão ser organizados por meio da oferta de diferentes arranjos curriculares, conforme a relevância para o contexto local e a possibilidade dos sistemas de ensino, a saber:

I - linguagens e suas tecnologias;

II - matemática e suas tecnologias;

III - ciências da natureza e suas tecnologias;

IV - ciências humanas e sociais aplicadas;

V - formação técnica e profissional (BRASIL, 2017).

Nas nuances da reforma, apesar de haver uma movimentação do governo em disseminar ideias à sociedade, por via de propagandas do Ministério da Educação, de que os alunos poderão escolher qualquer um dos cinco itinerários, percebe-se que quem vai estabelecer qual ou quais itinerários de fato estarão disponíveis são os sistemas de ensino que, em função da Emenda Constitucional $n^{\circ}$ 95/2016, não 


\section{D usm

poderão aumentar custos de pessoal. Assim, é possível afirmar que as escolas só poderão ter uma opção, em função da existência ou não de professores efetivos.

A reforma de ensino médio proposta por essa gestão no país elimina a conquista do ensino médio como educação básica universal para a grande maioria de jovens e adultos, por volta de $85 \%$ dos que estão na escola pública; agride diretamente à Constituição de 1988 e à Lei de Diretrizes da Educação Nacional que garantem a universalidade do ensino médio como etapa final de educação básica (FRIGOTTO, 2016).

Essas concepções de formação no ensino médio não são fato novo na conjuntura educacional brasileira, mas se manifestam nos últimos cincos anos, de modo que o Ministério da Educação e os Conselhos de Secretários de Educação vem defendendo a flexibilização dos percursos formativos, permitindo que o aluno, assegurado à base formativa comum, possa optar por um itinerário formativo, ou seja, aprofundar as bases acadêmicas ou a formação técnica profissional, a partir de seu projeto de vida (KUENZER, 2017).

Traz para o contexto das políticas educacionais algumas incertezas em termos da oferta de uma educação profissional de nível médio, na acepção de uma formação integral em que possa formar jovens de maneira multidimensional, desenvolvendo seus diferentes aspectos sociais, políticos, pessoais, culturais e etc.

E nesse cenário, situam-se as políticas de permanência no âmbito dos Institutos Federais de Educação, a partir das reivindicações trazidas para o cenário político dos estudantes e suas entidades representativas, tendo em vista a demanda de permanência dos adolescentes, jovens e adultos que passaram a ocupar as vagas desta instituição provenientes desse processo de expansão.

\section{As políticas de permanência estudantis no instituto federal de educação do Pará}

As políticas de permanência estudantil nos Institutos Federais de Educação, oriundas do Decreto PNAES de 2010, oferecem aos alunos dos cursos de educação profissional de nível médio e outros ofertados pela instituição, que se inserem no quadro de vulnerabilidade social, a possibilidade de receber, entre suas ações, 


\section{Dism \\ ISSN: 1984-6444

recursos materiais e financeiros para auxiliá-los no percurso escolar e assim evitar sua evasão 4 .

O marco histórico dessas políticas está situado nos movimentos estudantis da década de 1980, representados pelas lutas da União Nacional dos Estudante - UNE e pelo Fórum Nacionais de Pró-Reitores em Assuntos Comunitários e Estudantis FONAPRACE (2011), que diagnosticaram a necessidade dos estudantes das instituições federais de ensino de serem atendidos com ações de política de permanência escolar.

A partir do Decreto no 7.234/2010, os Institutos Federais de Educação passam a receber recursos da política em questão, identifica-se que, por meio dos gestores da assistência estudantil da rede, reivindicam no ano de 2013 a reconfiguração da política de assistência estudantil, em respeito à especificidade dos institutos e por ser também uma instituição de educação básica.

O Movimento ocorrido no I Seminário de Gestores da Assistência Estudantil da Rede Federal (2013) propunha a alteração do texto do PNAES para atenção às características dos Institutos Federais de Educação, considerando que:

[...] o texto atual não é explícito com relação à participação dos estudantes, de todas as modalidades de ensino, da Rede Federal EPTC no PNAES, fato que tem gerado insegurança jurídica em nossos Instituições e em alguns casos inviabilizado ações da Assistência Estudantil (IFMG, 2013, p. 04, grifo nosso).

Os Institutos Federais de Educação não se limitam a ofertar apenas cursos superiores, foco do decreto, mas ofertam a educação profissional em diferentes níveis e modalidades, dos cursos de formação inicial e continuada, cursos de educação profissional de nível médio, graduação e pós-graduação, latu e strito sensu, atendem uma diversidade de público e faixa etária, fato este que precisa da atenção da rede no sentido de conduzir a gestão dessa política considerando essa peculiaridade.

Desse modo, no âmbito da Rede em questão, há um movimento para consolidação dessa política no interior de cada instituto. No caso do IFPA, identificase desde de 2012 a Resolução no 134/CONSUP/IFPA, que dispõe sobre a política de

\footnotetext{
${ }^{4}$ No âmbito do IFPA, há recentemente, a partir de 2016, a implementação de uma política institucional, que caminha em prol de ações de permanência e êxitos dos alunos que é representada pela Política de Permanência e Êxito. Ver Resolução CONSUP/IFPA 513/2018.
} 
assistência ao educando, e considerou a política como princípios e diretrizes que orientam a elaboração e implementação das ações visando o êxito dos discentes, garantindo acesso, permanência e conclusão de cursos do IFPA.

Em busca de aprimoramento, recentemente o CONSUP ${ }^{5}$ do IFPA aprovou uma nova normativa para a política, a Resolução no 147 de 08 de dezembro de 2016, com discussões proporcionadas antes a sua aprovação, junto aos campi e às equipes de assistência estudantil, como o Fórum de Assistência Estudantil e nos encontros organizados pela Pró-Reitoria de Ensino - PROEN/IFPA e Departamento de Assistência Estudantil e Ações Inclusivas - DEPAI do IFPA ocorrido no ano de 2016. A atual resolução subsidia os campi do IFPA na implementação à política.

A normativa apresenta a Política de Assistência Estudantil - PAE do IFPA como um conjunto de princípios e diretrizes que devem orientar a construção de programas e projetos da assistência estudantil, com o objetivo de proporcionar ao estudante acesso, permanência e êxito acadêmico (IFPA, 2016, Art. $\left.2^{\circ}\right)^{6}$.

Nos objetivos da PAE/IFPA, destacam-se que devem contribuir aos aspectos vinculados à permanência e ao desempenho acadêmico dos estudantes, bem como à formação integral, ressaltando-se a necessidade de priorizar os que estão em vulnerabilidade social:

Art. 8ํ São objetivos da política de assistência estudantil no IFPA:

I - contribuir para o acesso, permanência e êxito no percurso educacional, prioritariamente àqueles em situação de vulnerabilidade social;

II - proporcionar aos estudantes permanência e êxito no percurso educacional, por meio de programas e projetos que reduzam os efeitos das desigualdades sociais e econômicas, favorecendo o aprendizado ao longo do percurso formativo;

$[\ldots]$

\footnotetext{
${ }^{5}$ Conselho Superior, por sua vez, é um órgão consultivo e deliberativo, que tem em sua composição representantes dos diferentes segmentos da comunidade escolar, quais sejam: docentes; estudantes, inclusive os egressos; servidores técnico-administrativos; sociedade civil, representantes do MEC e do Colégio de Dirigentes, em uma representação de caráter paritário entre estes segmentos (MARTINS, 2017).

${ }^{6}$ A política e gestão da PAE do Instituto são de competência da Pró-Reitoria de Ensino e do Departamento de Assistência Estudantil e Ações Inclusivas (DAI). Prevê também a criação do Núcleo de Assessoramento da Assistência Estudantil do IFPA, um órgão de caráter consultivo e propositivo, composto por profissionais que atuam diretamente nas áreas de assistência estudantil dos campi (IFPA, 2016, Art. 11), para em conjunto discutirem sobre os assuntos relacionados com a PAE - IFPA.
} 


\section{Tusm \\ ISSN: 1984-6444

$\mathrm{V}$ - promover e ampliar a formação integral dos estudantes, estimulando o desenvolvimento, criatividade, reflexão crítica, intercâmbio cultural, esportivo, artístico, político, científico e tecnológico;

$\mathrm{VI}$ - proporcionar condições de igualdades de oportunidade no exercício das atividades acadêmicas. (IFPA, 2016, grifo nosso).

Nesse artigo, pode-se constatar a valorização do eixo temático permanência estudantil interligada ao desenvolvimento acadêmico e a formação integral, preconizando um percurso escolar no qual haja condições para que o aluno desenvolva todas as suas dimensões de sujeito, numa perspectiva multilateral (GRAMSCI, 1968), e supere os limites que fizeram parte de seus vínculos escolares iniciais que, no caso da educação profissional de nível médio, é profundamente iminente (TCU, 2012).

Destaca-se no Art. 15 da PAE do IFPA as ações prioritárias: moradia estudantil, alimentação, transportes e apoio pedagógico (material pedagógico). A resolução dá autonomia aos campi para planejar a PAE de acordo com sua realidade, diagnóstico e o que prevê o Plano de Permanência e Êxito (PPE) do campus, respeitando o que preconiza a resolução e os limites financeiros estipulados na forma de legislação orçamentária e financeira vigente (Art. 17).

As ações da PAE do IFPA, nos seus respectivos campi, devem ser discutidas com o Fórum Interno de Assistência Estudantil:

Art. 18 Em cada campus deverá ser constituído um Fórum Interno de assistência estudantil, como instância que irá acompanhar e propor diretrizes para a efetividade dos Programas da Assistência Estudantil. Art. 19 O Fórum Interno de assistência estudantil deverá ser um espaço permanente de debates e reflexões acerca da assistência estudantil no âmbito do IFPA, e poderá a qualquer tempo solicitar informações acerca do PAE aos respectivos responsáveis (IFPA, 2016, grifo nosso).

A partir da constituição de um fórum nos campi, há prerrogativas para discussão das demandas dos estudantes nas ações da PAE, o que aponta para um caminho de constituição democrática para o uso dos recursos, vinculados com seu público alvo, em contraponto com os objetivos reais de uma política focalizada que se preocupa apenas em fortalecer o individualismo em prol do projeto social que defendem, para atender apenas as demandas do mercado, uma vez que o fórum prevê a participação 


\section{Dism \\ ISSN: 1984-6444

de representantes de todas as turmas do campus, podendo ser constituído da seguinte forma:

Art. 20 Deverá compor o fórum:

Um represente do grêmio estudantil, se houver;

Um representante de cada turma;

Um representante do centro acadêmico ou do diretório acadêmico, se houver; A equipe de assistência estudantil do campus (IFPA, 2016).

Identifica-se que o IFPA apresenta elementos legais que dão subsídios para desenvolver a política nos diferentes níveis de oferta, em especial nos cursos de educação profissional de nível médio, que apresenta um maior número de matrícula, além de preconizar a necessidade de consultas sobre a aplicação dos recursos, que precisam ser levadas aos maiores interessados pela política, os alunos.

\section{As políticas de permanência estudantil: a visão dos alunos dos cursos de educação profissional de nível médio}

No Seminário de Gestores da Assistência Estudantil da Rede Federal (IFMG, 2013) originou-se um documento que identificou que nos Institutos Federais de Educação, Ciência e Tecnologia estruturaram-se, a priori, para atender os filhos dos trabalhadores de baixa renda, das diversas regiões onde se instalaram os institutos, contudo, a pauperização das classes médias e o elevado nível de ensino destas instituições, além de outros fatores, também colaboraram na agregação de estudantes oriundos de várias classes sociais.

Nesse sentido, o desafio da inclusão social aponta para a necessidade de se estabelecerem políticas de Assistência Estudantil que favoreçam a permanência e o êxito no percurso formativo e na inserção sócio profissional dos estudantes, particularmente para aqueles que necessitam das referidas políticas e/ou se encontram em situação de vulnerabilidade social (IFMG, 2013).

O campus do IFPA, onde se desenvolve a pesquisa, integra o conjunto dos 18 campi, localizados nas diversas regiões do Estado do Pará, fez parte da $2^{\text {a }}$ fase da expansão da rede. O campus tem cerca de 859 alunos matriculados no ano de 2017, nos cursos da educação profissional de nível médio, integrado e subsequente, apontando para a relevância da oferta de educação básica e profissional para os 


\section{Dism \\ ISSN: 1984-6444 \\ Ellubahá}

jovens, na perspectiva de educação integral prevista na Lei de criação dos Institutos (BRASIL, 2008).

O quantitativo de alunos, nos cursos de nível médio de informática e edificações no campus, respectivamente, são 290 e 120 alunos ativos. Deste universo, entrevistou-se 06 (seis) alunos: 04 (quatro) dos cursos técnicos integrado ao ensino médio (2 de informática e 2 de edificações) e 2 (dois) do curso de informática subsequente ao ensino médio, são alunos das faixas etárias de 15 a 23 anos de idade, atendidos pelas ações da PAE de auxílios financeiros: alimentação, transporte, moradia e transporte escolar, que possuem renda familiar em torno de um salário mínimo e meio, para atender suas famílias de 3 a 9 integrantes.

Por meio dos dados coletados, constata-se que estes adolescentes e jovens apresentam especificidades dos alunos que estudam nos cursos de educação profissional de nível médio, no âmbito do instituto, refletem a maioria de alunos das escolas públicas, que vivem com uma renda limitada para atender as necessidades básicas como o sustento familiar e, no caso destes alunos, que moram em locais distantes, como em outros municípios, ilhas e estradas, precisam custear parte do transporte para o acesso à instituição, à alimentação e ao aluguel, fato este também constatado no relatório de gestão do IFPA (2016).

Nas entrevistas, identificou-se os eixos de análises: implementação da política com a unidade de análise temática escolhas das ações PAE/IFPA, e no eixo concepção de políticas de permanência, elencou-se a unidade de análise temática permanência no curso.

$\mathrm{Na}$ abordagem do item anterior, apontou-se que a PAE/IFPA deve favorecer a consulta para a oferta das ações de permanência aos alunos, por meio do Fórum Interno de Assistência Estudantil no campus. Os alunos ouvidos em entrevistas tiveram seu ingresso entre o ano de 2015 e 2017, apresentaram seus posicionamentos em relação à escolha das ações a serem oferecidas via editais, como é previsto na PAE/IFPA (2016):

Olha as vezes, tem. Isso é discutido em algumas reuniões, que tem por aqui, só que nunca é posto em prática, sempre fica no papel as reivindicações dos estudantes [...] em algumas reuniões, eles falam sobre isso, mais a questão do atraso do auxílio que demora muito para sair as vezes! E essa 
pauta é abordada na reunião mais nunca é levado a sério. (DEPOIMENTO ORAL, AL017 , 2018, grifo nosso.).

Não, eu sei vagamente, eu já vi [...] no auditório uma votação de delegados, mas só que não ficou muito específico para mim porque era mais fechado, não ficou claro. [...] acho que foi representante de turno se eu não me engano. (DEPOIMENTO ORAL, AL02, 2018, grifo nosso)

Eu acho que foi em 2016 que teve uma reunião onde [...] falaram que era para gente levar as necessidades da turma em questão, o que fazer com o auxílio, foi uma vez, só era pra saber o que queria fazer como os auxílios, que até a minha ideia, como nesse tempo a gente ficava muito tempo aqui no IF, fazer um refeitório que pudesse nos contemplar melhor, que a gente pudesse sentar, que a gente não tem um refeitório, a gente tem aqui um hall né, tem uma lanchonete né, mas não tem cadeira suficiente para todos, mas eu acho que foi isso que tentaram fazer, mas que a gente deu ideia, mas que eles não aceitaram, mas assim qual é a minha necessidade hoje que eles perguntaram indiretamente, nunca houve. (DEPOIMENTO ORAL, AL04, 2018, grifo nosso).

Há o entendimento dos alunos de que precisam ser consultados sobre as escolhas das ações da PAE, entretanto, não consideram o momento como algo que reflete os seus interesses: 'nunca é levado a sério'; 'eles não aceitaram', 'não ficou muito específico', 'mas nunca houve'. Identifica-se que as ações das políticas não caminham em atenção àquilo que os alunos consideram importante para sua necessidade.

Institucionalmente no IFPA, o Fórum nasce a partir da Resolução nํ 134/2012 CONSUP/IFPA, também como determinações dos órgãos de controle, como o Tribunal de Contas da União (2012). Pressupõe-se a necessidade de ações educativas de incentivo a esta participação no âmbito da instituição, bem como de aprimoramento das práticas que favorecem o desenvolvimento de posturas políticas dos alunos em vista ao próprio objetivo da PAE.

Com a experiência anterior na coordenação da assistência estudantil, de uma das pesquisadoras, bem como na pesquisa de FONAPRACE (2011), sabe-se que os recursos para essa política não vêm de acordo com a necessidade dos estudantes das instituições federais de ensino, estes estão muito aquém da demanda de permanência do estudante, como, por exemplo, a oferta do restaurante estudantil, representada na fala da Aluna - AL 04 e reivindicados pelo mencionado fórum.

\footnotetext{
${ }^{7} \mathrm{Na}$ entrevista semiestruturada, contou-se com o depoimento oral de 06 alunos, identifica-se no texto os alunos pela sigla $\mathrm{AL}$, acrescentando a numeração $01,02,03,04,05,06$, para distingui-los.
} 


\section{T usm \\ ISSN: 1984-6444

Em pesquisa do FONAPRACE (2012), constatou-se que o valor repassado em 2012 é três vezes menor do que o valor resultante da base de cálculo do fórum, assim o valor requerido pela assistência estudantil é o de $R \$ 1.556 .797 .950$, enquanto que o orçamento das IFES de 2011 aproximou 504 milhões. Esta situação gera o desafio para as instituições no processo de implementação da política (NASCIMENTO, 2014).

Nas entrevistas, identifica-se uma aluna, do curso técnico em informática, subsequente ao médio, que apresenta como é a condução do Fórum Interno Estudantil:

Eles fazem uma reunião com o grêmio estudantil, professores e outros responsáveis pelo auxílio, para discutir a questão dos valores que será destinado para cada auxílio, qual a necessidade maior! Esse ano teve. (...) Uma reunião, eles chamaram, colocaram no site do IFPA para os alunos participarem para ter essa discussão, através dessa ação que eles vão ver realmente o que os alunos estão precisando, (...) para ver a distribuição dos valores, que vem um determinado recurso pra poder distribuir, esse ano eu não sei exato essa quantidade de bolsa, mais ano passado teve mais oferta de alimentação do que da moradia, esse ano diminuiu a alimentação e ofertaram mais a moradia, devido à demanda de alunos que moram na zona rural, nas ilhas que acabam vindo pra cá e precisam de auxílio moradia. (DEPOIMENTO ORAL, AL05, 2018, grifo nosso).

As discussões voltam-se para a questão dos valores a serem vinculados por auxílios, bem como para quais auxílios serão ofertados em vista a necessidade dos seus estudantes e o recurso disponível para isso. Todas as ações da política, em especial a dos auxílios alimentação, transporte e moradia, são decididas por meio do valor previsto para essas no orçamento anual (IFPA, 2016).

Preconiza-se a necessidade de o campus estar trabalhando mais efetivamente para que sejam estabelecidos esses diálogos junto aos estudantes beneficiados pelas políticas, apesar da limitação orçamentária imposta nos últimos anos para essa política. Indica-se a necessidade de favorecer no campus espaços de escutas contínuas dos alunos nos processos de implementação da política.

Em relação à concepção de políticas de permanência, nas falas dos alunos, prevaleceu a unidade de análise temática permanência no curso, como apresentado a seguir:

Se não fosse o auxílio talvez eu teria desistido, porque é muito difícil. Até porque no IF tem muito contraturno, aula sábado, então é complicado. (...) não tinha outro meio, eu tinha que vir para o IF, dinheiro para gasolina esse tipo de coisa, ajudou muito mais, ajudou (...) (DEPOIMENTO ORAL, AL01, 2018, grifo nosso). 
É, as vezes ajuda os alunos a permanecer no colégio (...) eu pelo menos se não tivesse auxílio, ia ser bem difícil eu permanecer aqui, porque todo fim de semana eu vou lá para o sítio dos meus pais, então, para pagar aluguel, assim, ia ser meio puxado. [...] O ônibus é importante, porque as vezes nem todos os alunos, tem como vim para a escola, os pais não têm como vir trazer as vezes, eu não tenho moto ou bicicleta para vim e moro longe, e fica difícil para pagar mototáxi. O auxílio dar suporte para eu vir morar aqui (...) eu não ia ter condições de pagar o aluguel todo mês, ia ficar meio puxado, provavelmente eu já teria desistido. Eu acho que ajuda bastante, porque se não tivesse a assistência estudantil eu precisaria trabalhar e seria mais difícil estudar, isso mexeria no meu rendimento escolar, pelo menos é isso que eu acho (DEPOIMENTO ORAL, AL02, 2018, grifo nosso).

[...] se eu não tivesse ganhado o auxílio talvez, como muitos outros meus amigos, desistiram por não ter esse acesso sabe? Muitos não conseguiram ganhar [...] ajudou muito mesmo, assim o pouco que eles estavam dando me ajudou. (DEPOIMENTO ORAL, AL04, 2018, grifo nosso).

[...] quando eu soube que tinha também o auxílio aqui eu decidi fazer o pedido, quando eu ganhei facilitou muito, porque foi uma ajuda em relação a moradia se não fosse o auxílio talvez eu tivesse desistido do curso, porque ficaria inviável ou eu teria que sair nove horas pra poder pegar o horário o escolar e eu ia perder praticamente dois horários, três horários, principalmente agora nesse segundo semestre os horários estão indo até dez e meia, onze horas, devido a carga horária das disciplinas, teve uma extensão maior do que do primeiro semestre. Então me ajudou bastante, tanto na alimentação quanto na moradia. [DEPOIMENTO ORAL, AL05, 2018, grifo nosso).

A concepção de política de permanência está relacionada à minimização das dificuldades socioeconômicas que afetam diretamente a permanência no curso, sem a qual os alunos não estariam na instituição. Auxílios como alimentação, transporte e moradia, são as necessidades imediatas destes estudantes, uma vez que a organização curricular dos cursos técnicos de nível médio da instituição exige dos alunos que estejam por um tempo prolongado na instituição, nos turnos extensos ou mesmo nos contra turnos, e em aulas no sábado, devido a especificidades dos cursos técnicos integrados que possuem uma grade curricular extensa.

Dore et al. (2014) identificou que os fatores causadores da evasão são complexos e multifacetados na educação profissional, entre os fatores há os relacionados às questões socioeconômicas dos estudantes, questões pedagógicas e institucionais, uma vez que os jovens da escola média muitas vezes precisam escolher entre trabalhar e estudar, apresentam limites em sua formação no ensino fundamental 


\section{Uism \\ 〜 \\ Eulloabato}

ou mesmo as instituições não oferecem suporte para que possam ter uma formação ampla.

Dessa maneira, percebe-se avanços e desafios no processo de implementação da política, bem como na sua consolidação enquanto promotor do processo de enfrentamento da evasão na instituição; reconhece-se que a política está se estruturando na instituição por meio de suas bases legais, cabendo aos sujeitos responsáveis por sua implementação darem dinamicidade a partir da valorização da participação cidadã dos estudantes na sua realidade e nos limites dos recursos a eles impostos.

Tal valorização precisa estar atrelada à concepção do jovem enquanto sujeito de direito e agente de mudanças sociais, referendando-os enquanto protagonistas neste processo de constituição das políticas de permanência nas instituições federais de ensino, os quais devem a princípio participar dessa implementação, visto que a educação profissional deve formar na perspectiva de formação cidadã e favorecer ações que estimulem a atuação política.

\section{Considerações finais}

Com a contextualização da educação profissional e a expansão da rede federal de educação profissional, identificou-se os caminhos e descaminhos da política para essa modalidade de educação. Há um avanço quantitativo dos números de campi dos institutos. Mas seu projeto educativo pautado na concepção de formação integral pode enfraquecer em vista a reforma do ensino médio e a emenda constitucional n 95 (BRASIL, 2016) de contenção de gastos públicos.

Dentro desse contexto, os documentos que norteiam a PAE no IFPA, apresentam mecanismos de participação dos alunos na escolha das ações pela constituição do Fórum. A pesquisa no campus por meio das entrevistas, constatou a visão dos alunos em relação ao processo de escolha das ações, que entendem se tratar de consultas feitas, mas que não são valorizadas pelos gestores da política no campus. Preconiza-se que esta instituição precisa aprimorar o mecanismo de participação estudantil, para que estes tomem conhecimento das limitações de 


\section{T usm \\ ISSN: 1984-6444

recursos impostas ao gestor da política das instituições federais de ensino, como identificado pelo FONAPRACE (2012).

Ao mesmo tempo em que se reconhece a política como uma das promotoras de permanência no curso, uma vez que viabiliza a equidade educativa para que possam estar presente e desenvolver as atividades de maneira a superar limitações de cunho materiais, nota-se a percepção de que a política também precisa superar a concepção de ser apenas transferência de recursos financeiros, via auxílios.

Contudo, as políticas sociais estão envolvidas nas contradições de um estado capitalista que oferece o mínimo para o enfrentamento das problemáticas que levam o jovem a não permanecer na escola, atribuindo às instituições escolares a responsabilidade de implementar a política com recursos insuficientes, quando as outras instituições públicas de caráter social não oferecem os demais serviços como assistência social, moradia, saneamento, emprego e etc.

\section{REFERÊNCIAS}

ANDRÉ, Marli. Pesquisa em educação: buscando rigor e qualidade. Cadernos de Pesquisa, n.113, p. 51-64, jul. 2001. Disponível em: <http://nead.uesc.br/arquivos/Biologia/modulo_7_bloco_1/tcc/texto_2_pesquisa_em_ educacao_buscando_rigor_e_qualidade.pdf>. Acesso em: julho de 2017.

BRASIL. Constituição da República Federativa do Brasil. Brasília: Senado Federal, Centro Gráfico, 1988.

BRASIL. Lei no 9.394, de 20 de dezembro de 1996. Lei de Diretrizes e Bases da Educação Nacional. 1996.

BRASIL. Decreto № 2.208 DE 17 DE ABRIL DE 1997. Regulamenta o §2 do art. 36 e os artigos 39 a 42 da Lei 9.394, de 20 de dezembro de 1996, que estabelece as diretrizes e bases da educação nacional. 1997.

BRASIL. Decreto $n^{\circ} 5.154$, de 23 de julho de 2004. Regulamenta o § 20 do art. 36 e os arts. 39 a 41 da Lei no 9.394, de 20 de dezembro de 1996, que estabelece as Diretrizes e Bases da Educação Nacional, e dá outras providências. 2004.

BRASIL. Lei no 11.892, de 29 de dezembro de 2008. Lei de Criação da Rede Federal de Educação Profissional, Científica e Tecnológica e dos Institutos Federais de Educação, Ciências e Tecnologia. 2008. Disponível em: 


\section{A HEM \\ $\sim$

<http://www.planalto.gov.br/ccivil_03/_ato2007-2010/2008/lei/l11892.htm>. em: 11 abr. 2017.

BRASIL. Decreto no 7.234, de 19 de julho de 2010. Dispõe sobre o Programa Nacional de Assistência Estudantil - PNAES. Diário Oficial da União, Brasília, Seção 1, n. 137, p. 5, 20 jul. 2010.

BRASIL. Instituto Federal de Educação Profissional e Tecnológica: Concepções e Diretrizes. Brasília, 2010b.

BRASIL. Emenda constitucional ํo 95 de 2016. Altera o Ato das Disposições Constitucionais Transitórias, para instituir o Novo Regime Fiscal, e dá outras providências. 2016.2 Disponível em: https://www2.camara.leg.br/legin/fed/emecon/2016/emendaconstitucional-95-15dezembro-2016-784029-publicacaooriginal-151558-pl.html. Acesso: em setembro de 2018.

BRASIL. Lei no 13.145, de 16 de fevereiro de 2017. Altera a Lei no 9.394, de 20 de dezembro de 1996, que estabelece as diretrizes e bases de 1996, que estabelece as diretrizes e bases da educação nacional. 2017. Disponível: http://www.planalto.gov.br/ccivil_03/_ato2015-2018/2017/lei/l13415.htm. Acesso em novembro de 2017.

CUNHA, Luiz Antônio. O ensino profissional na erradicação do industrialismo. São Paulo: Editora UNESP, Brasília, DF: Flacso, 2000.

DORE, Rosemary et al. Evasão nos cursos técnicos de nível médio da rede federal de educação profissional de Minas Gerais. In: DORE, Rosemary et al. (Org.). Evasão na educação: estudos, políticas e propostas de enfrentamento. Brasília: IFB/CEPROTEC/RIMEPES, 2014. Disponível em: <http://www.fae.ufmg.br/rimepes/livros/Dore\%20et\%20al.\%20-\%202014\%20$\% 20$ Evasao\%20na\%20educacao\%20\%20estudos,\%20politicas\%20e\%20propostas.pdf>. Acesso em: abr. 2017.

FONAPRACE. Perfil Socioeconômico e Cultural dos Estudantes de Graduação das Universidades Federais Brasileiras. Fórum Nacional de Assuntos Comunitários e Estudantis (FONAPRACE). Brasília, 2011.

Revista comemorativa 25 anos: histórias, memórias e múltiplos olhares. Brasília: ANDIFES; UFU, PROEX: 2012.

FRIGOTTO, Gaudêncio; CIAVATTA, Maria; RAMOS, Marise. A gênese do Decreto n. 5.154/2004: um debate no contexto controvertido da democracia restrita. In: FRIGOTTO, Guadêncio; CIAVATTA, Maria; RAMOS, Marize. (orgs.). Ensino Médio Integrado: concepções e contradições. 3ª ed. São Paulo: Cortez, 2012. 


\section{T usm \\ ISSN: 1984-6444

FRIGOTTO, Guadêncio. Reforma de ensino médio do (des) governo de turno: decreta-se uma escola para os ricos e outra para os pobres. 2016. Entrevista. Disponível em: <http://www.anped.org.br/news/reforma-de-ensino-medio-do-desgoverno-de-turno-decreta-se-uma-escola-para-os-ricos-e-outra>. Acesso em: novembro de 2017.

GRAMSCI, A. Os Intelectuais e a organização da cultura. Rio de Janeiro: Civilização Brasileira, 1968.

INSTITUTO FEDERAL DO PARÁ - IFPA. Resolução no 189-CONSUP/IFPA. Plano de desenvolvimento Institucional do IFPA - PDI (2014-2018). Belém, 2014. Disponível em: <http://www.ifpa.edu.br/consup>. Acesso em: mar. 2017.

INSTITUTO FEDERAL DO PARÁ - IFPA. Resolução no 134/2012. Regulamenta a Política de Assistência ao Estudante do IFPA. Consul. 2012. Disponível em: $<$ https://ifpa.edu.br/documentos-institucionais/pdf-2012/378-leia-na-integra-aresolucao-n-134-2012-consup-de-04-de-dezembro-de-2012/file>. Acesso em: Maio de 2017.

INSTITUTO FEDERAL DO PARÁ - IFPA. Resolução no 147/2016. Regulamenta a Política de Assistência Estudantil no IFPA. CONSUP. 2016. Disponível em: $<w w w . i f p a . e d u . b r / p r o r e i t o r i a d e e n s i n o>$. Acesso em: maio de 2017.

INSTITUTO FEDERAL DO PARÁ -IFPA. Relatório de Gestão do Exercício de 2016. 2017. Disponível em: http://prodin.ifpa.edu.br/gestao/relatorio. Acesso em: junho de 2018.

INSTITUTO FEDERAL DE MINAS GERAIS - IFMG. I Seminário de Gestores da Assistência Estudantil da Rede Federal, 2013.

KUENZER, Acácia Zeneida. Trabalho e escola: a flexibilização do ensino médio no contexto do regime de acumulação flexível. Educ. Soc., Campinas, v. 38, ㄲo. 139, p.331-354, abr.-jun., $2017 . \quad$ Disponível em: <http://www.scielo.br/scielo.php?pid=S0101$73302017000200331 \&$ script=sci_abstract\&tIng=pt.. . Acesso em: novembro de 2017.

MARTINS, Luciana Paiva de Freitas Coêlho. A política de assistência ao educando do IFMA: uma avaliação política da política. 2017. 177 f. Dissertação (Mestrado) Programa de Pós-Graduação em Políticas Públicas, Universidade Federal do Maranhão, São Luís, 2017.

MANFREDI, Maria Silva. Educação Profissional no Brasil: atores e cenário ao longo da história. Jundiaí. Paco Editorial. 2017. 


\section{A HEM \\ $\sim$

NASCIMENTO, Clara Martins do. A assistência estudantil consentida na contrarreforma universitária dos anos 2000. Universidade e Sociedade. Sindicato Nacional dos Docentes das Instituições de Ensino Superior. Ano XXIII, nํㅜ 53. 2014.

REDE FEDERAL DE EDUCAÇÃO PROFISSIONAL, CIENTÍFICA E TECNOLÓGICA. Expansão da Rede Federal. $2016 . \quad$ Disponível: <http://redefederal.mec.gov.br/expansao-da-rede-federal>. Acesso em: novembro de 2017.

SHIROMA, Eneida Oto; MORAES, Maria Célia Marcondes De; EVANGELISTA, Olinda. Política Educacional. $4^{a}$ ed. Rio de Janeiro: Lamparina, 2011. Disponível: <http://www.ced.ufsc.br/nucleos/nup/perspectiva.html>. Acesso: novembro de 2017

TRIBUNAL DE CONTAS DA UNIÃO - TCU. Secretaria de Fiscalização e Avaliação de Programa de Governo. Relatório de auditoria da Rede Federal de Educação Profissional Científica e Tecnológica. Brasília, 2012. Disponível em: $<$ http://portal.tcu.gov.br/lumis/portal/file/fileDownload.jsp?inline=1\&fileld=8A8182A14 D92792C014D92847E5F3E97>. Acesso em: 25 abr. 2017.

TRIVIÑOS, Augusto N. S. Introdução à pesquisa em ciências sociais: a pesquisa qualitativa em educação. 9. ed. São Paulo: Atlas, 1987.

VIANA, Daniella Araujo Facchini. O programa de assistência estudantil e a cidadania: perspectivas dos alunos do ensino técnico integrado ao médio. Dissertações. 200 pág. Centro Universitário das Faculdades Associadas de Ensino, São João da Boa Vista, 2016. Disponível em: $<$ https://sucupira.capes.gov.br/sucupira/public/consultas/coleta/trabalhoConclusao/vi ewTrabalhoConclusao.jsf?popup=true\&id_trabalho=4932573>. Acesso em: 10 de maio de 2018.

\section{Correspondência}

Maria Cristina Afonso Ferreira -Instituto Federal do Pará, Av. Alm. Barroso, 1155. CEP: 66093-020. Belém, Pará, Brasil.

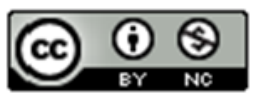

This work is licensed under a Creative Commons Attribution-NonCommercial 4.0International (CC BY-NC 4.0) 